\title{
Role of leukotrienes in bronchial hyperresponsiveness and cellular responses in airways
}

\author{
Alan R Leff
}

\section{Department of Medicine, Pediatrics, Pharmacological and Physiological Science, Anesthesiology and Critical Care, Committees of Cell Physiology and Clinical Pharmacology and Section of Pulmonary and Critical Care Medicine, The University of Chicago, Chicago, IL 60637, USA \\ A R Leff}

Reprinted from the American fournal of Respiratory and Critical Care Medicine 2000;161(Suppl):S125-32.

Correspondence to: Dr A R Leff aleff@ medicine.bsd.uchicago.edu

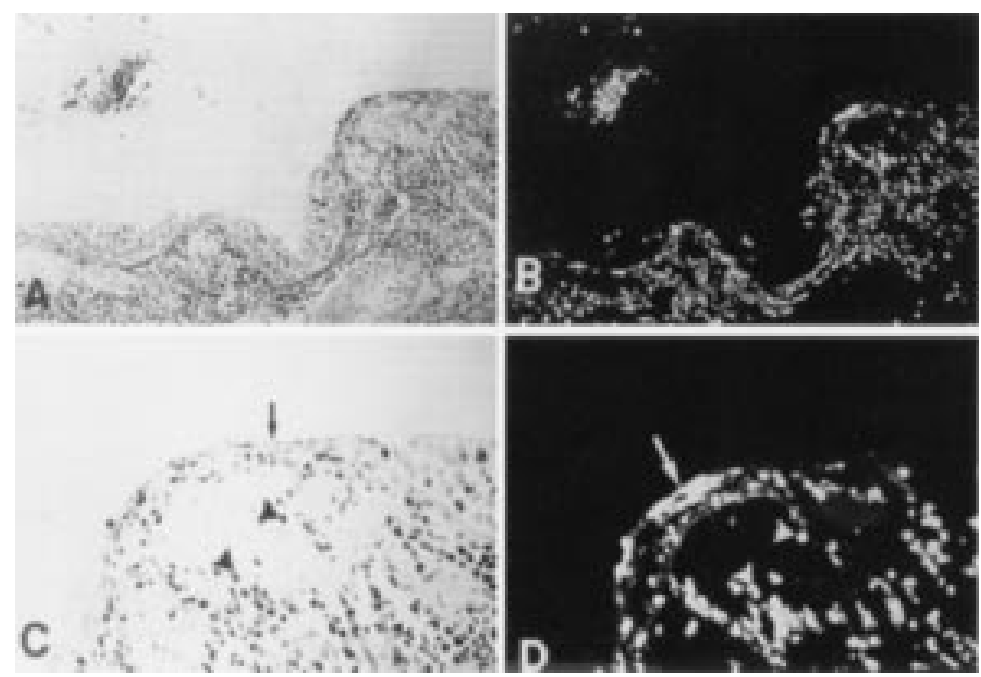

Figure 1 Effect of eosinophil infiltration into human airways. At later stages a cytotoxic effect probably accounts for the epithelial denudation found in human asthma. (A) Histological section of the airway of a patient with asthma (stain: haematoxylin-eosin, original magnification $\times 160$ ). (B) Same section stained with fluorescent monoclonal antibody for the eosinophil major basic protein $(M B P$; magnification $\times 160)$. (C) Higher power view of the desquamated epithelium in $(A)$ (basal magnification $\times 400)$. (D) Localisation of MBP in cells (arrowheads); these cells correspond directly to the cells marked in (C). MBP is also localised outside cells in association with epithelial desquamation (arrow; original transformation $\times 400$ ). (C) and (D) illustrate the identical area; this section was first stained for $M B P$ by immunofluorescence and subsequently stained with haematoxylin-eosin. Reprinted with permission from Gleich." of normal individuals, but may be found in massive numbers during periods of airway hyperresponsiveness in asthmatic individuals (fig 1). ${ }^{3-5}$ Most experimental models indicate that eosinophils are an invariable component of asthmatic hyperresponsiveness, although some occur in the relative absence of these cells.

For the purposes of this discussion, the eosinophil will be viewed as a leukotriene transport system capable of providing a substantial reservoir of bronchoactive leukotrienes to airways in relatively short time. They may be delivered to conducting airways in large numbers and have the capacity to produce cysteinyl leukoneutrophils, but also migrate into conducting airways in some circumstances. ${ }^{67}$ This discussion deals first with the mechanism by which eosinophils, a minority constituent of the circulating blood, are honed selectively to the conducting airways of the lung in human

Among constitutively present cells, bronchoactive leukotrienes are produced predominantly by mast cells ${ }^{1}$ and macrophages. ${ }^{2}$ A unique characteristic of asthmatic inflammation is the migration of leukocytes from the peripheral blood to the conducting airways of eosinophil, which is not present in the airways 
of the lung during periods of asthmatic activity $^{15} 16$ and this cytokine selectively causes shedding of L-selectin from the eosinophil surface and the simultaneous upregulation of $\beta_{2}$-integrins on the eosinophil surface. The nature of the process that causes relatively quiescent asthma to enter a phase of eosinophil recruitment is not defined. While it is presumed that the initial secretion of IL- 5 is Th2 cell mediated, the trigger for this event is also unknown. Once activated, eosinophils further produce IL-5, and this suggests a possible autocrine amplification of the recruitment process.

The next phase of this recruitment process is tight adhesion of eosinophil integrins to surface ligands on the endothelium. $\beta_{1}$-integrin (VLA-4) is constitutively expressed on the eosinophil surface; whether its conformation is changed to augment adhesion is unknown. $\beta_{2}$-integrin expression is quantitatively upregulated by a mechanism directly related to binding at the IL-5 receptor (fig 2). Preliminary data (unpublished) suggest that the conformation of MAC-1, a $\beta_{2}$-integrin, is also altered toward a higher affinity state by IL-5. As noted above, upregulation of these integrins by IL- 5 does not occur for the neutrophil, which lacks the IL-5 receptor, and this may account for the selective migration of eosinophils, which share $\beta_{2}$-integrins, MAC-1 and LFA-1 with neutrophils.

The counterligands for eosinophil surface integrins are the immunoglobulin (Ig) supergenes ICAM-1 $\left(\beta_{2}\right)$ and VCAM-1 $\left(\beta_{1}\right)$ which are endothelial surface molecules containing a 5-domain transmembrane component. The

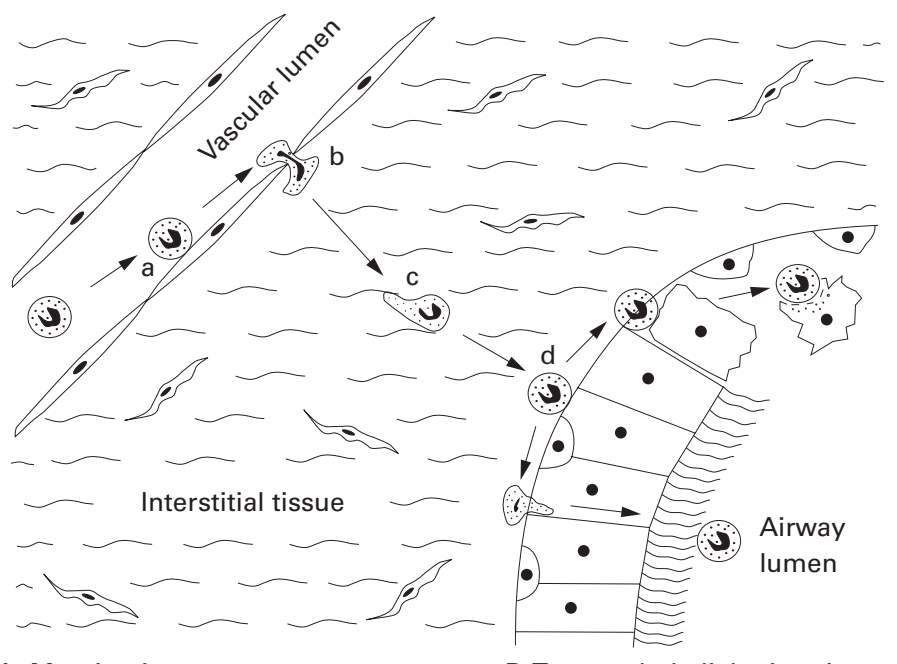

A Margination

B Transendothelial migration

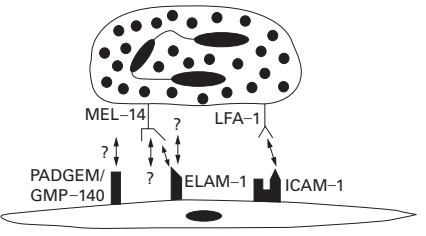

Endothelium

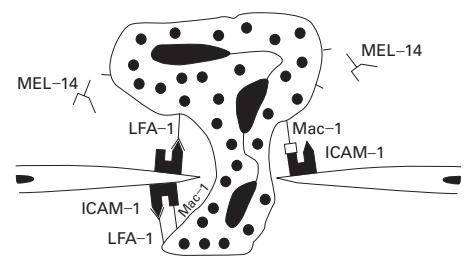

Figure 2 Adhesion of a granulocyte to the endothelial wall. Lower: "Rolling" function caused by selectin molecules is followed by tight adhesion to ICAM-1 by $\beta_{2}$-and $\beta_{1}$-integrin (not shown). Lower right: This leads to diapedesis through the endothelial cell wall into the airway parenchyma. Reprinted with permission from Wegner and Hamann. ${ }^{10}$

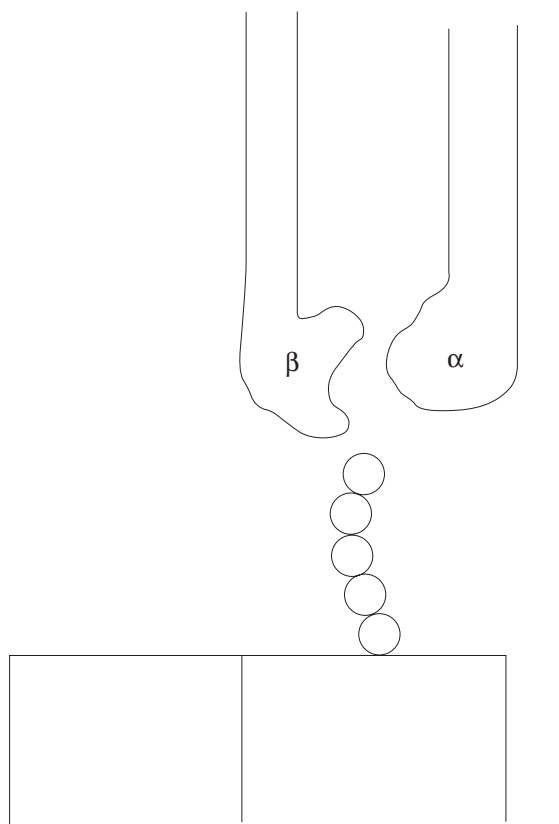

Figure 3 Schematic characterisation of the ligation between integrins on the eosinophil surface (left side) and immunoglobulin supergenes (e.g. ICAM-1,VCAM-1) on the endothelial surface. Specificity of binding is determined by the conformation of the $\alpha$ and $\beta$ chains into which the terminal portion of the 5-domain transmembranous portion of the immunoglobulin supergene fits.

specificity for binding between integrins and endothelial surface ligands is determined by the pocket formed by the $\alpha$ and $\beta$ chains of the surface integrin (fig 3) into which the ICAM-1 or VCAM-1 molecule inserts. As for eosinophil surface integrins, Ig supergenes are upregulated by specific cytokines including IL-1 and IL-4. ${ }^{17}{ }^{18}$ The "trigger" for this process remains similarly unknown. It is not known whether $\beta_{1^{-}}$ or $\beta_{2}$-integrins further participate in the selectivity of eosinophil recruitment. $\beta_{1}$ integrin is present only on the surface of eosinophils and lymphocytes, but not neutrophils. On the other hand, blockade of $\beta_{2}$-integrin is sufficient to prevent eosinophil migration both in vitro and in vivo (see below).

\section{Relationship between eosinophil} recruitment and augmented synthesis of leukotrienes

Another unique property of eosinophils is their ability to ligate to matrix protein within the airway wall. VLA-4, which is not present on neutrophils, binds specifically to the RGD region of fibronectin (FN) (fig 4), and this binding also does not occur for neutrophils. Several investigations have examined the relationship between binding to $\mathrm{FN}$ in vitro and the stimulated synthesis of $\mathrm{LTC}_{4}$ using isolated human eosinophils incubated with FN coated microwell plates. The binding process is remarkably slow (60 min; fig 5) compared with binding to cultured human umbilical vein endothelial cells (about $5 \mathrm{~min}$ ), suggesting that the molecule(s) may need to change conformation in the process. However, once binding has occurred there is a substantial augmentation of stimulated eosinophil secretion of LTC $_{4}$. Figure 6 indicates that overall secretion increases 


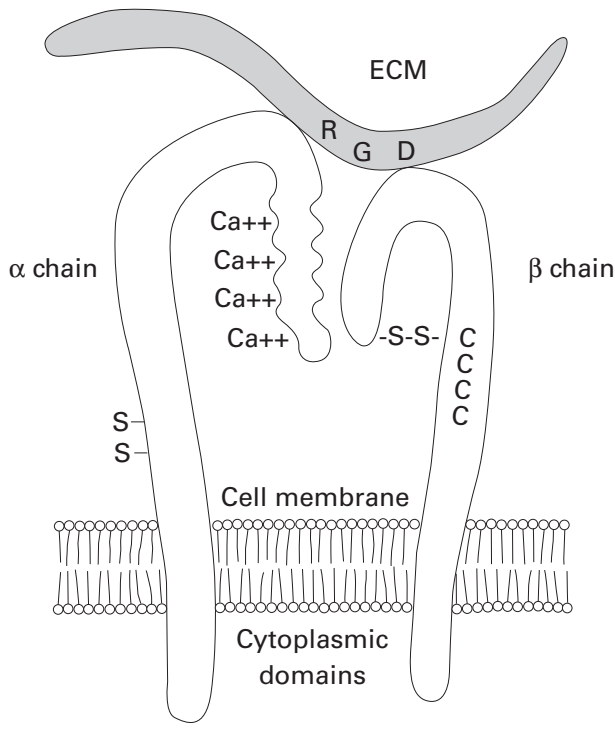

Figure 4 Schematic characterisation of the ligation between VLA-4 with its characteristic $\alpha_{4} \beta_{1}$ chains and the $R G D$ region on fibronectin which causes intramural binding of eosinophils following diapedesis. Adapted from Wegner and Hamann. ${ }^{10}$

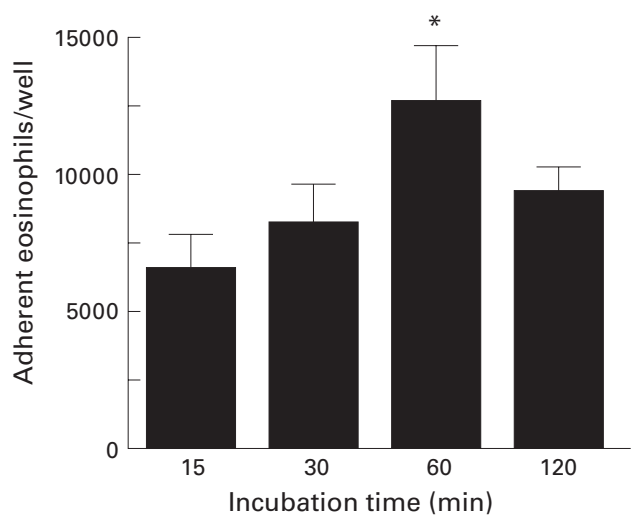

Figure 5 Time course of binding of eosinophils to fibronectin (FN) coated microwell plates. Significant binding requires incubation for $60 \mathrm{~min}$, which is substantially longer than for binding to endothelial ICAM-1 by the same eosinophil surface ligand (see text). Reprinted with permission from Neeley et al. ${ }^{20}$

by about $40 \%$; however, given that only about $20 \%$ of the cells are actually bound in these studies, augmentation of $\mathrm{LTC}_{4}$ secretion in bound cells may be estimated to be about fivefold. There are preliminary data to suggest that ligation of both $\beta_{1}$ - and $\beta_{2}$-integrin to the endothelial surface also augments eosinophil secretion of $\mathrm{LTC}_{4} \cdot{ }^{19}$ Thus, the process of cellular transmigration that accompanies chemoattraction of eosinophils into the airway matrix appears to be the process by which eosinophil synthesis of leukotriene synthesis is primed. The precise mechanism by which adhesion ligation causes this priming is unknown but is currently under active investigation.

\section{Physiological consequences of augmented secretion}

The notion that eosinophils could exist as innocent bystanders in the process of asthmatic hyperresponsiveness has been addressed in several experimental situations. The mere presence of these cells, even if the association

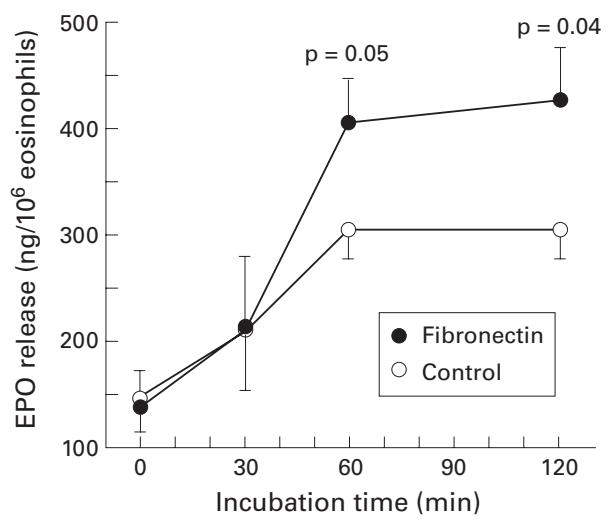

Figure 6 Augmented secretion caused by priming due to ligation of eosinophil VLA-4 and fibronectin. EPO = eosinophil peroxidase. Reprinted with permission from Neeley et al. ${ }^{20}$

were invariable, does not implicate their physiological significance in the bronchoconstrictor process. As noted above, it would appear that in some circumstances eosinophil infiltration is not essential to produce a substantial bronchoconstrictor response-for example, exercise induced bronchoconstriction. A question to be resolved is whether the transmigration of eosinophils into airways and the concurrent priming of leukotriene secretion is at least capable of causing constriction of airways. If quantities of leukotriene secreted are insufficient, or if blockade of eosinophil infiltration has no effect on airway responsiveness, the eosinophil might well be an innocent bystander.

Prior investigation in monkeys sensitised with Ascaris suum antigen have shown that eosinophils migrate into sensitised airways. ${ }^{21}$ Blockade of this migration with anti-ICAM-1 antibody both reduced the number of infiltrating eosinophils and substantially reduced the airway hyperresponsiveness on bronchial challenge. This would suggest that, under these experimental circumstances, eosinophils are essential to airway hyperreactivity (fig 7). In guinea pig tracheal preparations, eosinophils isolated from either normal donors or cultured from human umbilical vein cord blood elements cause substantial contraction (fig 8 ) that is blocked completely with inhibitors of 5-lipoxygenase, the enzyme converting arachidonic acid into $\mathrm{LTA}_{4}$ which precedes production of $\mathrm{LTC}_{4}$. By contrast, comparable activation of isolated human neutrophils has no effect on guinea pig tracheal contraction (fig 9).

To test further whether activated human eosinophils could cause contraction of human airway smooth muscle, our laboratory developed a system for videomicrometry of small sections of human airways. Fifth to seventh generation airways can be incubated in 96 well microplates. The airways are photographed through an overhead microscope and the images are stored in real time on a computer. Changes in airway diameter are measured by determining lumenal pixel fitting in a manner described by Schmidt and Rabe. ${ }^{24}$ Exposure to progressively larger numbers of human eosinophils causes progressive contraction as 
A

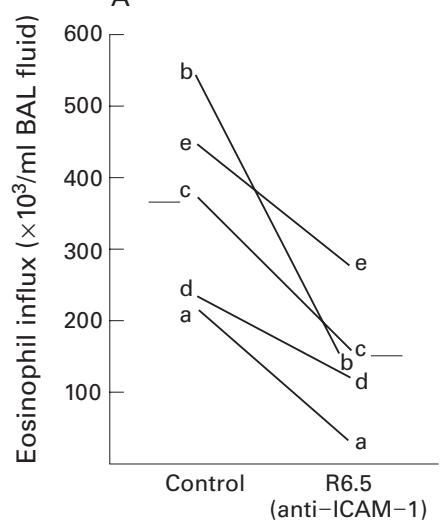

B

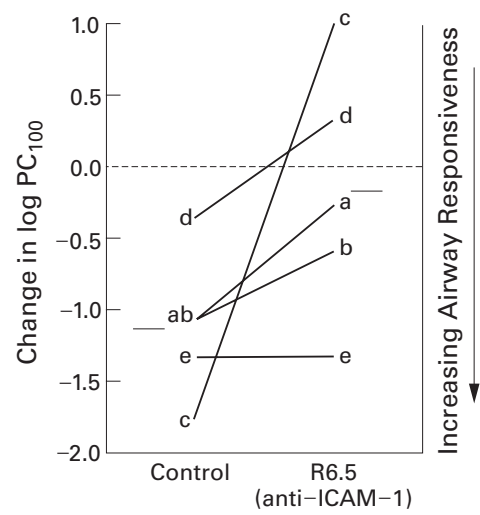

Figure 7 Relationship between inhibition of eosinophil migration caused by ICAM-1 and airway hyperresponsiveness in monkeys sensitised with Ascaris suum antigen. Blockade of eosinophil migration is associated with return of airway hyperresponsiveness to near normal levels. Reprinted with permission from Leff et al. ${ }^{15}$
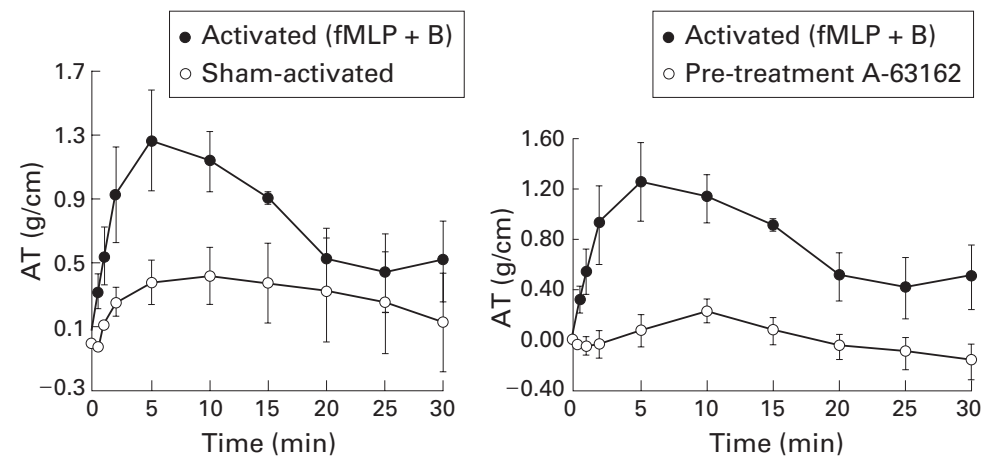

Figure 8 Effect of activated eosinophils cultured from human cord blood on isometric tone in guinea pig trachealis muscle in vivo. Human cells were activated first with $f M L P+$ cytochalasin $B$ and then applied directly to the trachea. Force is expressed as isometric tension per unit area of the tracheal surface. AT = active tension. Reprinted with permission from Hamann et al. ${ }^{22}$

measured by lumenal narrowing. ${ }^{25}{ }^{26}$ This narrowing was blocked completely by pretreatment with the 5-lipoxygenase inhibitor A63162, a cogener of the drug zileuton which is now marketed in the United States for the treatment of asthma.

To determine whether the degree of augmentation of secretion of leukotriene caused by adhesion of isolated human eosinophils to $\mathrm{FN}$ also caused augmented contraction of human airways, the effect on airway narrowing in human airway sections using isolated human eosinophils was examined. Cells exposed to FN caused a twofold greater narrowing of lumenal area than cells exposed to bovine serum albumin (BSA) as a control (fig 10). Contraction was blocked completely for both BSA and FN treated cells activated with formyl-met-leu-phe (fMLP) + cytochalasin B by pretreatment with the 5-lipoxygenase inhibitor A63162. ${ }^{27}$ Contraction of airways in all studies was elicited with $10^{5}$ cells. While these data do not predict the in vivo situation, they do indicate that a physiologically meaningful augmentation of human airway contraction is elicited by adhesive ligation. However, given the dramatic nature of the blockade of the contractile effects caused by eosinophils in this system, it is perhaps somewhat disappointing that anti-leukotriene therapies are less efficacious than would be predicted from these

A fMLP + vehicle

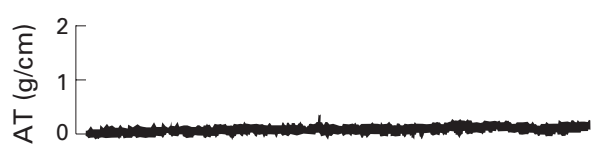

B fMLP activated HL60 cells

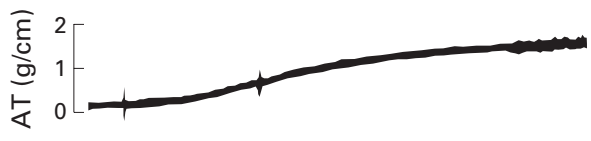

C fMLP activated neutrophils

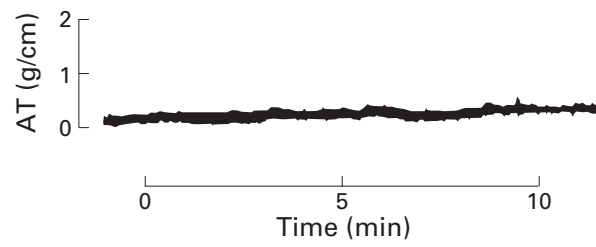

Figure 9 Effect of human neutrophils activated as in fig 8 on isometric tone in guinea pig trachealis. There is no contractile effect caused by the activating substance $\mathrm{MLP}$ given alone or by fMLP activated neutrophil (compared with fig 8 for eosinophils). Neutrophils lack the enzyme to produce cysteinyl leukotrienes. Positive controls are HL-60 cells, which produce bronchoconstriction prostaglandins, but not leukotrienes. $A T=$ active tension. Reprinted with permission from Munoz et al. ${ }^{23}$

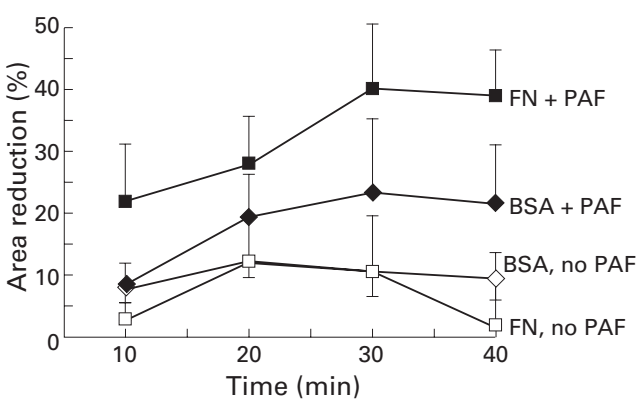

Figure 10 Effect of fibronectin (FN) ligation of human eosinophils on contraction of human bronchial explants in vitro. There is substantial augmentation of lumenal narrowing in $F M L P$ activated human eosinophils first exposed to FN vs controls exposed to bovine serum albumin (BSA). Exposure of eosinophils to FN alone had no contractile effects. Hence, adhesion molecule ligation has a priming rather than a direct stimulatory effect on airway smooth muscle contraction. $P A F=$ platelet activating factor. Reprinted with permission from Munoz et al. ${ }^{27}$

models. These data indicate that the process of asthmatic bronchoconstriction is substantially more complicated than that which can be predicted by a single in vitro model in an isolated cell system.

\section{Leukotrienes in chemotaxis}

Leukotrienes have variable chemotactic properties that are highly cell dependent. There is also a strong species dependence which make data from other species unreliable for prediction of the human condition. The guinea pig eosinophil is rich is $\mathrm{LTB}_{4}$ receptors and hence is highly chemotactic in a variety of experimental systems. ${ }^{13}$ However, the human eosinophil (as noted above) is weakly attracted by $\mathrm{LTB}_{4}$, implying a weaker receptor population. By contrast, human neutrophils are strongly 


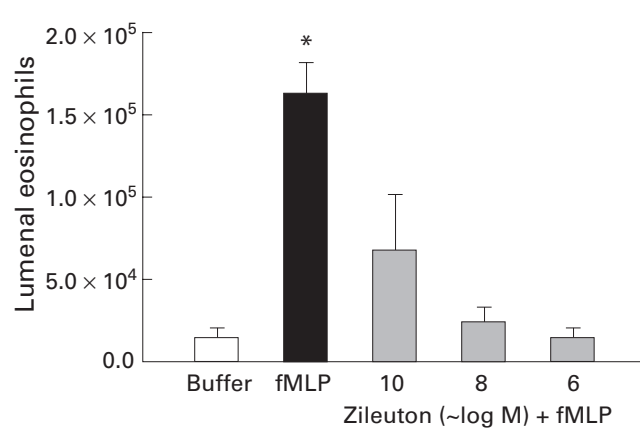

Figure 11 Effect of pretreatment with the 5-lipoxygenase inhibitor zileuton on eosinophil migration from the lamina propria to the lumen in guinea pig tracheal explants. Chemotaxis was initiated by lumenal instillation of $\mathrm{ALP}$. Reprinted with permission from Munoz et al. ${ }^{28}$

chemotactic and this was an initial concern in the development of anti-leukotriene treatments directed against 5-lipoxygenase. The specific concern was whether the concomitant blockade of $\mathrm{LTB}_{4}$ - as well as cysteinyl leukotriene synthesis - that results as a consequence of the blockade of 5-lipoxygenase might also prevent neutrophil chemotaxis. The system has proved to be more robust than feared, and there is no increase in significant respiratory infection when a 5-lipoxygenase agent is used compared with a leukotriene receptor antagonist that has no effect on $\mathrm{LTB}_{4}$. Unfortunately, there is also no evidence that eosinophil chemotaxis is selectively diminished by $\mathrm{LTB}_{4}$ inhibition resulting from synthesis inhibitors. Hence, there is no obvious therapeutic benefit to drugs that block the entire leukotriene synthetic pathway over receptor antagonists that specifically block the cysteinyl leukotriene receptor.

A recently described phenomenon is the ability of the anti-leukotriene agents to block eosinophil migration, at least partially, even with short term use. In guinea pig tracheal explants, the chemotactic agent fMLP causes substantial and selective migration of eosinophils that reside naturally (and quiescently) in the lamina propria (fig 11). Administration of zileuton in concentrations of $>10^{-8} \mathrm{M}$ caused substantial inhibition of eosinophil migration, and full blockade was achieved with higher concentrations. ${ }^{13}$ Because $\mathrm{LTB}_{4}$ receptors are significantly involved in the chemotactic process, it was postulated that the action

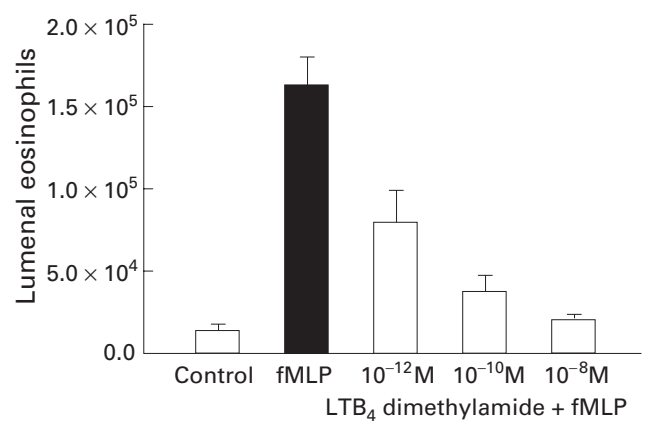

of zileuton resulted from the unique ability of this anti-leukotriene to block the synthesis of $\mathrm{LTB}_{4}$ as well as the SP1 analogues. The selective $\mathrm{LTB}_{4}$ antagonist $\mathrm{LTB}_{4}$ dimethylamide caused even more potent blockade of eosinophil migration in this model (fig 12). However, administration of the highly selective $\mathrm{LTD}_{4}$ receptor antagonist zafirlukast caused equipotent blockade. Significant inhibition of eosinophil chemotaxis was observed at $10^{-12} \mathrm{M}$ zafirlukast. Comparable trials have been conducted in humans. Calhoun et $a l^{29}$ have reported in a preliminary study that large doses of zafirlukast given over 24 hours caused an approximate $50 \%$ decrease in the migration of eosinophils into the airways of challenged asthmatic subjects, and Diamant et a ${ }^{30}$ have shown independently comparable findings.

The mechanism by which $\mathrm{LTD}_{4}$ receptor blockade inhibits eosinophil migration remains elusive. There are no cysteinyl leukotriene receptors on the eosinophil surface in either rodents or humans. Hence, the effect is either non-specific - that is, non-receptor related - or the result of complex interactions within the airway involving other cells and/or tissues. Based on the guinea pig model, the airway itself appears to contain all the elements necessary to inhibit eosinophil migration through blockade of the cysteinyl leukotriene receptor. One recent investigation using the leukotriene receptor antagonist pranlukast has shown that the ability of this compound to block eosinophil migration into the airways of challenged guinea pigs is blocked with the monoclonal antibody TRFK-5 which is directed against IL-5. ${ }^{31}$ This implies, but does not by any means establish, that blockade of the $\mathrm{LTD}_{4}$ receptor on some element contained within the airway wall could have an inhibitory effect on IL-5 secretion, which is an important component of adhesion model upregulation in eosinophil chemotaxis (see above). However, definitive studies are still required to elucidate the mechanism whereby $\mathrm{LTD}_{4}$ receptor blockade affects eosinophil migration. It also remains to be determined whether the magnitude of inhibition of eosinophil migration in humans is clinically and pathophysiologically significant. If so, anti-leukotriene therapies could properly be viewed as being broadly anti-inflammatory in a

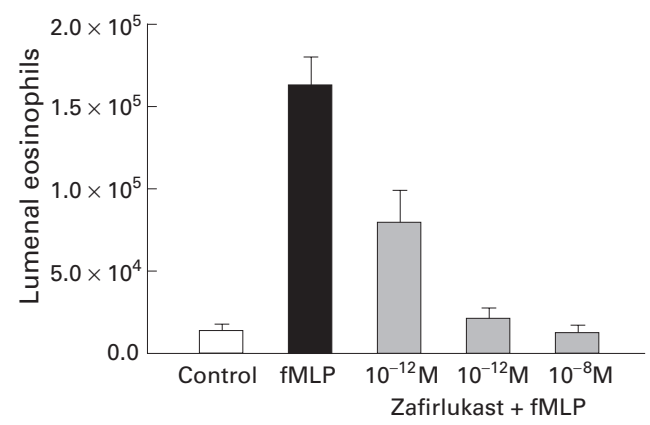

Figure 12 Effect of pretreatment with inhibitors of $\mathrm{LTB}_{4}$ and $\mathrm{LTD}_{4}$ on eosinophil chemotaxis using the same preparation as for fig 11. $\mathrm{LTB}_{4}$ causes inhibition of chemotaxis at even lesser concentrations than zileuton, suggesting that there is a chemotactic effect of this cysteinyl leukotriene compound. The mechanisms by which LTD causes chemoattraction in this model are undefined but similar findings are suggested from human studies (see text). Reprinted with permission from Munoz et al. ${ }^{28}$ 
manner (if not degree) comparable to that conferred by corticosteroid treatment. The implications of this for subsequent airway remodelling have been discussed elsewhere.

\section{Conclusions}

As asthma is viewed as an inflammatory process mediated at least in some part by leukotrienes, eosinophils are the major transport systems for these compounds to the airway smooth muscle where they cause contraction, and to the airway vasculature where they cause oedema. Leukotrienes are synthesised de novo in eosinophils directly from membrane phospholipids after activation by phospholipase $\mathrm{A}_{2}$ $\left(\mathrm{PLA}_{2}\right)$. The process of selective chemoattraction is a fascinating one, as eosinophils are but a minor component of the circulating granulocytes. Even though eosinophils share common surface ligands with neutrophils, they are capable of selective migration into the airway wall. It is likely that cytokine specific processes regulate this selective migration-for example, IL-5.

It is also of considerable interest that the process of molecular adhesion and transmigration is intimately linked to the priming of eosinophil secretion of leukotrienes. The mechanism by which this occurs is unclear, but appears from some very preliminary studies to be related to the direct phosphorylation of PLA $_{2}-\mathrm{IV}$, which may occur as a consequence of adhesion. Another property of leukotrienes that remains unexplained is the apparent ability of these compounds to cause, by a mechanism yet to be defined, substantial chemotaxis of eosinophils in both animal models and in humans.

While eosinophils are the unique inflammatory cells of asthmatic inflammation, it is still unclear if they are essential for all manifestations of the asthma syndrome. It is further unclear whether leukotriene synthesis alone accounts for the bioactivity of these cells in causing airway narrowing in asthma. Blockade of leukotriene activity in human asthma does not cause improvement in airflow obstruction in a manner comparable to that obtained with corticosteroids or high efficacy $\beta_{2}$ adrenoceptor drugs. The invariable presence of eosinophils in human asthma does not itself imply a role for these cells in the pathogenesis of the disease. However, the demonstration that adhesion primed eosinophils are capable of causing massive augmentation of leukotriene secretion and that this secretion is of a magnitude sufficient to cause contraction of human airway explants suggests that eosinophils are the source of leukotrienes in human asthma. Nonetheless, the roles of eosinophils and of leukotrienes in human asthma may vary among the different asthma phenotypes that are only now being defined.

1 Shimizu Y, Schwartz L. Mast cell involvement in asthma. In: Barnes P, Grunstein M, Leff A, Woolcock A, eds. Asthma. Philadelphia: Lippincott-Raven, 1972: 353-61.

2 Padrid PA, Wolf R, Spaethe S, et al. Selective attenuation by 5-lipoxygenase blockade of peripheral airway hyperresponsiveness and edema caused by activated alveolar macrophages. Am Rev Respir Dis 1993;147:1514-20.
3 Padrid P, Snook S, Finucane T, et al. Persistent airway hyperresponsiveness and histologic alterations after chronic 151:184-93.

4 Kroegel C, Liu MC, Lichtenstein LM, et al. Antigeninduced eosinophil activation and recruitment in lower airways. F Allergy Clin Immunol 1991;87:303.

5 Gleich GJ. The eosinophil and bronchial asthma: current understanding. F Allergy Clin Immunol 1990;85:422-36.

6 Kirby JG, Hargreave FE, Gleich GJ, et al. Bronchioalveolar cell profiles of asthmatic and non-asthmatic subjects. Am Rev Respir Dis 1981;136:370-83.

7 Jeffery PK, Wardlaw AJ, Nelson FC, et al. Bronchial biopsies in asthma: an ultrastructural, quantitative study and correin asthma: an ultrastructural, quantitative study and corre1745-53.

8 Albelda SM. Endothelial and epithelial cell adhesion molecules. Am f Respir Cell Mol Biol 1991;4:195-203.

9 Bevilacqua MP, Stengelin S, Gimbrone MA, et al. Endothelial leukocyte adhesion molecule 1: an inducible receptor for neutrophils related to compliment regulatory proteins and lectins. Science 1989;243:1160.

10 Wegner CD, Hamann KJ. Adhesion molecules. In: Leff AR, ed. Pulmonary and critical care pharmacology and therapeutics. New York: McGraw-Hill, 1996: 297-317.

11 Jackson WT, Boyd RJ, Froelich LI, et al. Specific inhibition of leukotriene B(4)-induced neutrophil activation by of leukotriene B(4)-induced neutrophil activation

12 Kishikawa K, Tateishi N, Maruyama T, et al. ONO-4057, a novel, orally active leukotriene $\mathrm{B}_{4}$ antagonist effects $\mathrm{LTC}_{4}-$ induced neutrophil functions. Prostaglandins 1992;44:26175 .

13 Munoz NM, Leff AR. Blockade of eosinophil migration by 5 -lipoxygenase and cycloxygenase inhibition in explanted guinea pig trachealis. Am f Physiol 1995;268:L446-54.

14 Silbaugh SA, Stengel PW, Williams GD, et al. Effects of leukotriene $\mathrm{B}_{4}$ inhalation airway sensitization and lung granulocyte infiltration in the guinea pig. Am Rev Respir Dis 1987;136:930-4.

15 Leff AR, Hamann K, Wegner C. Inflammation and cell-cell interactions in airway responsiveness. Am f Physiol: Lung Cell Mol Physiol 1991;260:L189-206.

16 Leff AR. Inflammatory mediation of airway hyperresponsiveness by peripheral blood granulocytes: the case for the eosinophil. Chest 1994;106:1202-8.

17 Albelda SM, Breck CA. Integrins and other cell adhesion molecules. FASEB f 1990;4:2868.

18 Masinovsky B, Urdal D, Gallantin WM. IL-4 acts synergistically with IL- $1 \beta$ to promote lymphocyte adhesion to microvascular endothelium by induction of vascular cell adhesion molecule-1. F Immunol 1990;145:2880.

19 Munoz NM, Herrnreiter A, Rabe KF, et al. Induction by interleukin (IL)-1 augments eosinophil secretion and lumenal narrowing of explanted human airways. $A m \mathcal{F}$ Respir Crit Care Med 1995;151:A369.

20 Neeley SP, Hamann KJ, Dowling KT, et al. Augmentation of stimulated eosinophil degranulation by VLA-4 (CD49d) mediated adhesion to fibronectin. Am f Respir Cell Mol Biol 1994;11:206-13.

21 Wegner CD, Gundel RH, Reilly P, et al. Intracellular adhesion molecule-1 (ICAM-1) in the pathogenesis of asthma. Science 1990;247:456-9.

22 Hamann KJ, Strek ME, Baranowski SL, et al. Effects of activated eosinophils cultured from human umbilical cord blood on guinea pig trachealis. Am F Physiol: Lung Cell Mol Physiol 1993;265:L301-7.

23 Munoz NM, Hamann KJ, Vita A, et al. Activation of racheal smooth muscle responsiveness by fMLP-treated HL-60 cells and neutrophils. Am F Physiol: Lung Cell Mol Physiol 1993;264:L222-8.

24 Schmidt D, Rabe KF. The role of leukotrienes in the regulation of tone and reponsiveness in isolated human airways. Am 7 Respir Crit Care Med 2000; 161 (Suppl 1): S62-7.

25 Galens S, Munoz NM, Rabe KF, et al. Assessment of agonist- and cell-mediated responses in airway microsections by computerized videomicrometry. Am $\mathcal{f}$ Physiol: Lung Cell Mol Physiol 1995;268:L519-25.

26 Mitchell RW, Rühlman E, Magnussen H, et al. Passive sensitization of human bronchi augments maximal shortening velocity and capacity of the smooth muscle. Am F Physiol: Lung Cell Mol Physiol 1994;267:L218-22.

27 Munoz NM, Rabe KF, Neeley SP, et al. Eosinophil VLA-4 binding to fibronectin causes augmented narrowing of human bronchial explants through 5-lipoxygenase activation. Am f Physiol: Lung Cell Mol Physiol 1996;270:L58794.

28 Munoz NM, Douglas I, Mayer D, et al. Eosinophil chemotaxis inhibited by 5-lipoxygenase blockade and leukotriene receptor antagonism. Am F Respir Crit Care Med 1997;155: $1398-403$.

29 Calhoun WJ, Lavins BJ, Minkowitz MC, et al. Effect of zafirlukast (Accolate) on cellular mediators of inflammazafirlukast (Accolate) on cellular mediators of inf

30 Diamant Z, Hilterman JT, van Rensen EL, et al. The effect of inhaled leukotriene $\mathrm{D}_{4}$ and methacholine on sputum cell differentials in asthma. Am $\mathcal{F}$ Respir Crit Care Med 1997; 155:1247-53.

31 Underwood DC, Osborn RR, Newsholme SJ, et al. Persistent airway eosinophilia after leukotriene (LT) $\mathrm{D}_{4}$ administration in the guinea pig: modulation by the $\mathrm{LTD}_{4}$ receptor antagonist, pranlukast, or an interleukin-5 monoclonal antibody. Am f Respir Crit Care Med 1996;154:850-7. 